\title{
The Association between the $K L F 14$ rs4731702 SNP and the Lipid Profile in Type 2 Diabetes Mellitus Patients: A Study in San Luis City, San Luis, Argentina
}

\section{Micaela Fernanda Álvarez, Miriam Ester Vásquez Gómez, Irma Inés González, Gustavo Fernández, Susana Siewert*}

Laboratory of Diabetes, Department of Biochemistry and Biological Sciences, School of Chemistry, Biochemistry and Pharmacy, National University of San Luis, San Luis, Argentina

Email: *ssiewert@unsl.edu.ar

How to cite this paper: Álvarez, M.F., Gómez, M.E.V., González, I.I., Fernández, G. and Siewert, S. (2016) The Association between the KLF14 rs4731702 SNP and the Lipid Profile in Type 2 Diabetes Mellitus Patients: A Study in San Luis City, San Luis, Argentina. Open Access Library Journal, 3: e3188.

http://dx.doi.org/10.4236/oalib.1103188

Received: November 1, 2016

Accepted: November 22, 2016

Published: November 25, 2016

Copyright $\odot 2016$ by authors and Open Access Library Inc.

This work is licensed under the Creative Commons Attribution International License (CC BY 4.0)

http://creativecommons.org/licenses/by/4.0/

\section{(c) (i) Open Access}

\begin{abstract}
The single nucleotide polymorphism (SNP) rs4731702 in the KLF14 transcription factor gene has been associated with type 2 diabetes mellitus (T2DM) and HDL-c concentrations. The aim of the present study was to determine the distribution of KLF14 rs4731702 SNP and evaluate the association between this SNP and serum lipid profile in T2DM patients in a patient population at San Luis province, Argentina. A total of 73 volunteers (26 T2DM patients and 47 healthy age-matched controls) were genotyped for KLF14 rs4731702 SNP by Tetra Primer ARMS-PCR. The KLF14 genotypes distribution among study groups was not significantly different. In T2DM patients, there was a difference in HDL-c values and TC/HDL-c ratio, with $\mathrm{T}$ carriers of the rs4731702 SNP (non C/C) having higher HLD-c and lower TC/HDL-c ratio values than $\mathrm{C} / \mathrm{C}$ homozygotes $(\mathrm{p}=0.0047$ and 0.0041 , respectively). HDL-c levels were higher in diabetic patients, without dyslipidemia, carrying the genotype non$\mathrm{C} / \mathrm{C}(\mathrm{p}=0.023)$. Conversely, TC and LDL-c levels were lower in diabetic patients, without dyslipidemia, in non-C/C carriers $(\mathrm{p}<0.001)$. The results of the current study showed that T2DM is characterized by dyslipidemia, and that the alterations observed in the lipoprotein might be related to lower KLF14 activity in diabetic patients as a consequence of $\mathrm{C} / \mathrm{C}$ genotype and insulin resistance.
\end{abstract}

\section{Subject Areas}

Medical Genetics

\section{Keywords}

KLF14, Single Nucleotide Polymorphism, Type 2 Diabetes Mellitus, Lipid Profile, 
Dyslipidemia

\section{Introduction}

Type 2 diabetes mellitus (T2DM) is a chronic disease also known as adult-onset diabetes or non-insulin-dependent diabetes. It accounts for more than $90 \%$ of all diabetes cases in the global population. Without proper monitoring, it can lead to serious complications such as cardiovascular, kidney, nervous, and eye diseases; including death. T2DM is a life-long condition that requires careful nutritional and pharmacologic managements. The incidence and prevalence of T2DM has reached epidemic proportions worldwide and is increasing [1].

Insulin resistance and abnormal insulin secretion are the hallmark of T2DM. Metabolic syndrome is defined as a cluster of metabolic disturbances that include insulin resistance, abdominal obesity, hyperglycemia, hypertension, and dyslipidemia. This syndrome is common in poorly controlled T2D patients. Although environmental factors, particularly caloric excess and physical inactivity, play major roles in metabolic syndrome, the traits are highly heritable [2].

Large-scale genome-wide association studies (GWAS) have identified that a genetic variant on chromosome 7 is strongly associated with both HDL trait and CHD [3] [4] [5] [6] [7]. This variant lies in a non-coding region in the vicinity of $K L F 14$, which encodes the transcription factor KLF14 (Kruppel-like factor 14). KLF14 is a member of a large family of zinc-finger transcription factors that has been widely studied in embryogenesis, cell proliferation, differentiation, and development. The $18 \mathrm{KLFs}$ described in mammals possess highly conserved cysteine and histidine zinc fingers, critical for recognition and binding to CACCC or CGCCC DNA motifs [8].

$K L F 14$ may acts in trans to regulate the expression of a network of genes controlling several metabolic traits (e.g., LDL-c, HDL-c, TG and BMI) [9]. Variants near the maternally-expressed transcription factor $K L F 14$ are robustly associated with both T2DM and HDL-c concentration in GWAS. These studies have implicated a group of highlycorrelated SNPs including rs4731702 approximately $14 \mathrm{~kb}$ upstream of the transcription-starting codon of the KLF14 gene [4] [10].

In addition, functional studies found that the maternally transmitted $\mathrm{T}$ allele of rs4731702 is associated with increased expression of KLF14 in adipose tissue (rs4731702 acts in cis to influence $K L F 14$ expression). All these evidences indicate that this $K L F 14$ variant is an important regulator of lipoprotein metabolism [11].

The present study was aimed at determining the distribution of rs4731702 SNP genotypes and evaluates its association with serum lipid profile in T2DM patients.

\section{Research Design and Methods}

\subsection{Study Population}

The present study was carried out in accordance with the guidelines of the Helsinki 
Declaration. A total of 73 volunteers (26 T2DM patients and 47 healthy age-matched controls) participated in this study. Criteria published by the Report of the Committee on the Classification and Diagnostic Criteria of Diabetes Mellitus were used to diagnose T2DM [12]. These patients resided in San Luis, Argentina. The protocol for the present study was approved by the local Institutional Review Board, and written informed consent was obtained from each patient to be enrolled. Exclusion criteria included renal, hepatic or brain-vascular disorders, endocrinal disorders, women receiving estrogen therapy and chronic disorders, as well as the use of lipid-lowering drugs, which can affect glucose metabolism and/or insulin sensitivity. All participants were recruited consecutively between March 2015 and March 2016.

\subsection{Anthropometric and Clinical Data}

For each enrolled participant, height $(\mathrm{H}, \mathrm{m})$, weight $(\mathrm{W}, \mathrm{kg})$ and waist circumference (WC; $\mathrm{cm}$ ) were measured. Height and weight were measured to the nearest $0.5 \mathrm{~cm}$ and $0.1 \mathrm{~kg}$, respectively. The body mass index (BMI) was calculated as weight divided by height squared $\left(\mathrm{kg} / \mathrm{m}^{2}\right)$.

\subsection{Definitions}

The criteria for weight classification by BMI were according to the Clinical Guidelines on the Identification, Evaluation, and Treatment of Overweight and Obesity in Adults [13]. Participants were classified according to the following criteria: Underweight is defined as BMI $<18.5 \mathrm{~kg} / \mathrm{m}^{2}$, Normal as BMI between $18.5-24.918 .5 \mathrm{~kg} / \mathrm{m}^{2}$, Overweight as BMI between $25.0-29.9 \mathrm{~kg} / \mathrm{m}^{2}$, Type I Obesity as BMI between $30.0-34.9 \mathrm{~kg} / \mathrm{m}^{2}$, Type II Obesity as BMI between $35.0-39.9 \mathrm{~kg} / \mathrm{m}^{2}$ and Type III Obesity as BMI $\geq 40.0 \mathrm{~kg} / \mathrm{m}^{2}$.

\subsection{Blood Sampling}

Blood samples were obtained from patients that had fasted overnight for a minimum of $12 \mathrm{~h}$. Blood was collected in tubes containing $0.1 \%$ ethylenediaminetetraacetic acid. Plasma and blood cells were separated by centrifugation at $1400 \times \mathrm{g}$ for $20 \mathrm{~min}$ at room temperature. Plasma and packed blood cells were aliquoted and stored at $-20^{\circ} \mathrm{C}$ until use.

\subsection{Biochemical Measurement}

Fasting plasma glucose (FPG) was measured by using a glucose oxidase method with a commercial enzymatic kit (Wiener Laboratories, Rosario, Argentina). Total cholesterol (TC), triglycerides (TG) and HDL-c concentrations were measured using commercial kits by following the manufacturer's instructions (Wiener Laboratories, Rosario, Argentina). LDL-cholesterol (LDL-c) and VLDL-cholesterol (VLDL-c) were calculated with the Friedewald formula: LDL-c $=$ TC $-($ HDL-c + TG/5) in mg/dL and VLDL-c $=$ $\mathrm{TG} / 5$ in $\mathrm{mg} / \mathrm{dL}$ [14].

\subsection{Definitions}

The criteria for dyslipidemia were according to the National Cholesterol Education 
Program [15]. Briefly, participants were diagnosed with dyslipidemia if they had one or more of the following criteria: a plasma concentration of TC of $\geq 6.24 \mathrm{mmol} / \mathrm{L}(\geq 240$ $\mathrm{mg} / \mathrm{dL}$ ), plasma concentration of $\mathrm{TG} \geq 2.26 \mathrm{mmol} / \mathrm{L}$ ( $\geq 198 \mathrm{mg} / \mathrm{dL}$ ); plasma concentration of HDL-c of $<1.04 \mathrm{mmol} / \mathrm{L}(<40 \mathrm{mg} / \mathrm{dL})$ for men or $<1.30 \mathrm{mmol} / \mathrm{L}(<50 \mathrm{mg} / \mathrm{dL})$ for women; and a plasma concentration of LDL-c $\geq 4.14 \mathrm{mmol} / \mathrm{L}(\geq 160 \mathrm{mg} / \mathrm{dL})$.

\subsection{DNA Samples}

Genomic DNA was isolated from T2DM patients and healthy volunteers using conventional protocol by Qiagen kits (Qiagen, Inc., Valencia, CA). DNA concentration was measured by UV-VIS spectroscopy and diluted to a final concentration of 20 $\mathrm{ng} / \mu \mathrm{L}$.

\subsection{Primer Design, Amplification, and Genotyping of Tetra Primer ARMS-PCR}

Based on the GenBank sequence of human KLF14, accession number NT_007933.15, we designed "in silico" a pair of outer primers and two allele-specific inner primers using the Tetra Primer ARMS-PCR, in a free access web

(http://cedar.genetics.soton.ac.uk) and then checked for specificity (http://blast.ncbi.nlm.nih.gov/Blast.cgi) (Table 1).

Each PCR reaction was carried out in a total volume of $20 \mu \mathrm{L}$, containing $180 \mathrm{ng}$ of template DNA, $0.06 \mathrm{pmol}$ of inner primer $\mathrm{C}$ allele, $0.12 \mathrm{pmol}$ of inner primer $\mathrm{T}$ allele, $0.06 \mathrm{pmol}$ of reverse outer primer, $0.12 \mathrm{pmol}$ of forward outer primer, $200 \mu \mathrm{M}$ dNTPs, $1.5 \mathrm{mM} \mathrm{MgCl}_{2}, 1 \times$ buffer, and 1 unit of Taq Pegasus DNA polymerase (Productos Bio-Logicos, Argentina). The template DNA was denatured for 3 minutes at $95^{\circ} \mathrm{C}$ before undergoing 35 cycles of denaturation for 1 minute at $95^{\circ} \mathrm{C}$, primer annealing for 1 minute at $62^{\circ} \mathrm{C}$ and extension for 1 minute at $72^{\circ} \mathrm{C}$, and final extension at $72^{\circ} \mathrm{C}$ for 3 minutes (Table 1). The resultant amplicons were separated by electrophoresis onto a 2.5\% agarose gel-bed containing GelRed. The image was visualized and photographed under UV transillumination. Randomly selected $20 \%$ of samples were re-genotyped for

Table 1. PCR primers and conditions.

\begin{tabular}{|c|c|c|c|}
\hline $\begin{array}{c}\text { Genetic } \\
\text { polymorphism }\end{array}$ & Primer sequence & $\begin{array}{l}\text { Annealing } \\
\text { temperature }\end{array}$ & $\begin{array}{l}\text { Amplicon } \\
\text { size }\end{array}$ \\
\hline \multirow{3}{*}{ rs4731702 (C/T) } & $\begin{array}{l}\text { Forward inner primer (C allele): } \\
\text { 5'AAAAAACAGCATTATTTCCCACACAAAC3' }\end{array}$ & $62^{\circ} \mathrm{C}$ & $\begin{array}{c}515 \mathrm{pb} \\
(\mathrm{C} \text { allele })\end{array}$ \\
\hline & $\begin{array}{c}\text { Reverse inner primer (T allele): } \\
\text { 5’TATCTTTTTGGTGCTAAATGGAACGGA3' }\end{array}$ & & $\begin{array}{l}158 \mathrm{bp} \\
\text { (T allele) }\end{array}$ \\
\hline & $\begin{array}{c}\text { Forward outer: } \\
\text { 5'CCCAAGGCATCTATCCAAAA3' } \\
\text { Reverse Outer: } \\
\text { 5'CCGTTGAACTGTGTTTGCAC3' }\end{array}$ & & $\begin{array}{l}619 \mathrm{bp} \\
\text { (from two } \\
\text { outer } \\
\text { primers) }\end{array}$ \\
\hline
\end{tabular}


cross validating initial genotypes. Whenever, genotyping results were unclear, the samples were repeated again in duplicates until clear genotype was obtained. No genotyping error was observed during cross validation (Figure 1).

\subsection{Statistical Analysis}

The chi-squared test was used to check adjustment of the data to the Hardy-Weinberg equilibrium, and to compare the allelic frequencies between controls and T2DM patients. Statistical analyses were carried out in both groups of patients. Data are shown as mean values \pm standard deviation (SD), absolute values or percentages (\%). To analyze the association between KLF14 genotypes, clinical and biochemical parameters, a Student's $t$-test was used when variables were continuous, whereas a Fisher's exact test was used for the categorical variables. STATA version 6 (StataCorp LP, College Station, TX, USA) was used for statistics. A p $<0.05$ was considered to be statically significant.

\section{Results}

\subsection{Participant Characteristics}

Table 2 shows the demographic characteristics of both groups. 50.7\% were women and 49.3\% were men, age distribution was not different between the groups. There was a significant difference in BMI between control and T2DM patients.

Figure 2 shows the classification of BMI according to the World-Health Organization in both groups, there were more overweight and obese patients in the T2DM group than in the control group.

As shown in Table 3, fasting plasma glucose concentration was higher in the T2DM group as compared to the age-matched control group. T2DM patients have higher TG, LDL-c and VLDL-c, whereas lower HDL-c concentrations than controls. Furthermore, the TG/HDL-c ratio-an indicator of insulin resistance, and of the proportion of small

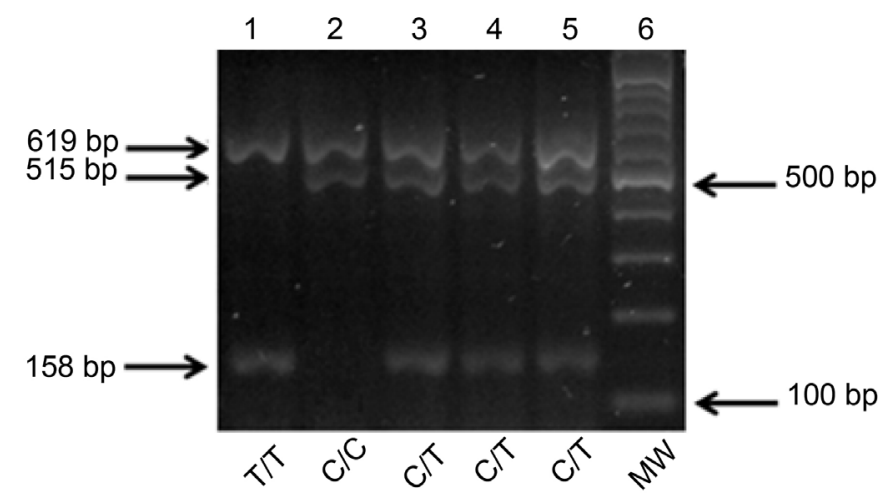

Figure 1. KLF14 genotyping by Tetra Primer ARMS-PCR. The 619 bp band is the amplicon of the outer primers, the 515 bp band, of an outer primer and the inner primer for allele C; and the 158 bp band, of the other outer primer and the inner primer for the $\mathrm{T}$ allele. Lane 1 : $\mathrm{T} / \mathrm{T}$ genotype; lane 2: $\mathrm{C} / \mathrm{C}$ genotype; lanes 3, 4 and 5: $\mathrm{C} / \mathrm{T}$ genotype; lane 6: molecular weight marker. 


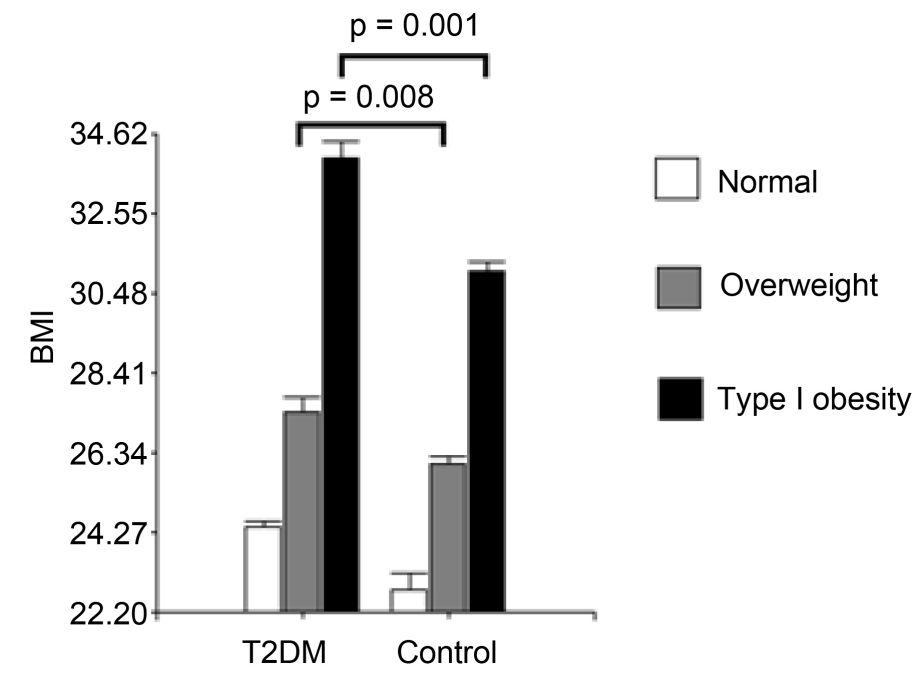

Figure 2. Classification of BMI according to WHO for T2DM and control groups. Data are shown as mean \pm SEM.

Table 2. Anthropometric characteristics in control and T2DM patients.

\begin{tabular}{cccc}
\hline & $\begin{array}{c}\text { Control } \\
(\mathbf{n}=47)\end{array}$ & $\begin{array}{c}\text { T2DM } \\
(\mathbf{n}=26)\end{array}$ & P \\
\hline Sex (female/male) & $24 / 23$ & $13 / 13$ & 1.000 \\
Age (years) & $55.68 \pm 11.36^{*}$ & $57.31 \pm 11.90$ & 0.175 \\
Weight (kg) & $76.27 \pm 13.43$ & $75.47 \pm 11.11$ & 0.6801 \\
Height (m) & $1.69 \pm 0.09$ & $1.68 \pm 0.10$ & 0.3109 \\
BMI $\left(\mathrm{kg} / \mathrm{m}^{2}\right)$ & $26.19 \pm 3.69$ & $28.13 \pm 3.46$ & 0.0438 \\
\hline
\end{tabular}

${ }^{\star}$ Data are shown as mean \pm standard deviation. BMI: body mass index.

Table 3. Biochemical characteristics in control and T2DM patients.

\begin{tabular}{cccc}
\hline & $\begin{array}{c}\text { Control } \\
(\mathrm{n}=47)\end{array}$ & $\begin{array}{c}\text { T2DM } \\
(\mathrm{n}=26)\end{array}$ & $p$ \\
\hline FPG $(\mathrm{mg} / \mathrm{dL})$ & $88.21 \pm 10.02$ & $158.79 \pm 80.87$ & $<0.0001$ \\
TG (mg/dL) & $144.52 \pm 83.60$ & $215.52 \pm 107.73$ & 0.0041 \\
TC (mg/dL) & $184.77 \pm 47.50$ & $196.91 \pm 44.76$ & 0.3687 \\
HDL-c (mg/dL) & $49.95 \pm 8.63$ & $41.24 \pm 4.81$ & $<0.0001$ \\
LDL-c (mg/dL) & $121.59 \pm 38.35$ & $101.66 \pm 38.91$ & 0.0363 \\
VLDL-c (mg/dL) & $27.57 \pm 16.02$ & $42.27 \pm 13.71$ & 0.0003 \\
TG/HDL-c ratio & $2.70 \pm 1.43$ & $5.80 \pm 1.43$ & $<0.0001$ \\
TC/HDL-c ratio & $4.01 \pm 0.89$ & $5.18 \pm 1.34$ & 0.0003 \\
Dyslipidemia & $31.58 \%$ & $71.43 \%$ & 0.0018 \\
\hline
\end{tabular}

Data are shown as mean \pm standard deviation. FPG, fasting plasma glucose; TG, triglycerides; TC, total cholesterol; HDL-c, high-density lipoprotein; LDL-c, low-density lipoprotein; VLDL-c, very low-density lipoprotein. 
and dense LDL-c particles, reaches high positive values in T2DM group, in contrast to low levels in control group. The TC/HDL-c ratio-an atherogenic index, was increased in the T2DM group, which suggests a higher risk of cardiovascular diseases in this group of patients.

\subsection{Genotype Frequencies}

Table 4 shows the frequency (\%) and absolute number of patients having each genotype in all patients, and in controls and T2DM patients by separate. KLF14 genotype distribution was in the Hardy-Weinberg equilibrium and comparable in both two groups. We found no-gender differences in either control or T2DM patients having the different genotypes. The frequency of the $\mathrm{T}$ allele of the KLF14 rs4731702 polymorphism in control was not different from that in $\mathrm{T} 2 \mathrm{DM}(\mathrm{p}=0.384)$.

\subsection{Inheritance Model}

When genotypes of KLF14 were associated with T2DM according to all possible genetic models, no association was found with T2DM according to any genetic model used (Table 5).

Table 4. Distribution of KLF14 genotypes and allelic frequencies in controls and T2DM patients.

\begin{tabular}{cccccc}
\hline Genotype & $\begin{array}{c}\text { Total } \\
(\mathbf{n}=\mathbf{7 3})\end{array}$ & $\begin{array}{c}\text { Control } \\
(\mathbf{n}=\mathbf{4 7})\end{array}$ & $\begin{array}{c}\text { T2DM } \\
(\mathbf{n}=\mathbf{2 6})\end{array}$ & OR(95\% CI) & p \\
\hline $\mathrm{C} / \mathrm{C}$ & $34 \%(25)$ & $30 \%(14)$ & $42 \%(11)$ & 1 & \\
$\mathrm{C} / \mathrm{T}$ & $48 \%(35)$ & $51 \%(24)$ & $42 \%(11)$ & $1.71(0.59-4.97)$ & 0.417 \\
$\mathrm{~T} / \mathrm{T}$ & $18 \%(13)$ & $19 \%(9)$ & $15 \%(4)$ & $1.77(0.43-7.30)$ & 0.501 \\
$\mathrm{C}$ & $0.58(85)$ & $0.55(52)$ & $0.63(33)$ & & \\
$\mathrm{T}$ & $0.42(61)$ & $0.45(42)$ & $0.37(19)$ & $1.714(0.59-4.97)$ & 0.384 \\
\hline
\end{tabular}

${ }^{\mathrm{a}} \mathrm{OR}=$ odds ratio, $95 \% \mathrm{CI}=95 \%$ confidence interval.

Table 5. Risk analysis of the variant rs4731702 KLF14 according to the model of inheritance.

\begin{tabular}{cccccc}
\hline Model $^{\mathbf{a}}$ & Genotype $^{\mathbf{b}}$ & $\begin{array}{c}\text { Control } \\
\mathbf{n}(\%)\end{array}$ & $\begin{array}{c}\text { T2DM } \\
\mathbf{n}(\%)\end{array}$ & $\mathbf{p}$ & $\begin{array}{c}\text { OR }^{\mathbf{c}} \\
(95 \% \mathrm{CI})\end{array}$ \\
\hline \multirow{2}{*}{ Co } & CC & $14(29.8)$ & $11(42.3)$ & & 1 \\
& CT & $24(51.1)$ & $11(42.3)$ & 0.56 & $1.71(0.59-4.97)$ \\
& TT & $9(19.1)$ & $4(15.4)$ & & $1.77(0.43-7.30)$ \\
Do & CC & $14(29.8)$ & $11(42.3)$ & 0.28 & $1.73(0.64-4.69)$ \\
& CT-TT & $33(70.3)$ & $15(57.7)$ & & 1 \\
Re & CC-CT & $38(80.8)$ & $22(84.6)$ & 0.68 & $1.30(0.36-4.73)$ \\
& TT & $9(18.5)$ & $4(15.4)$ & & 1 \\
Od & CC-TT & $23(48.9)$ & $15(57.7)$ & 0.47 & $1.42(0.54-3.74)$ \\
\hline
\end{tabular}

${ }^{a}$ Inherintance models: codominant (Co), dominant (Do), recessive (Re), overdominant (Od). ${ }^{\mathrm{b}} \mathrm{Genotypes}$ and their groupings for the variant rs $4731702 \mathrm{KLF14}(\mathrm{C}>\mathrm{T})$. ${ }^{\mathrm{c}} \mathrm{OR}=$ odds ratio, $95 \% \mathrm{CI}=95 \%$ confidence interval. 


\subsection{Genotype Associations with Lipid Traits}

The comparison of the anthropometric and clinical characteristics by the polymorphism KLF14 (rs4731702) in controls and T2DM are shown in Table 6. The low frequency of the $\mathrm{T} / \mathrm{T}$ genotype of the KLF14 polymorphism was analyzed in the same category as the corresponding heterozygotic genotype, namely as non-C/C (T carriers). No statistically significant associations with anthropometric and clinical characteristics were observed for this rs4731702-KLF14 polymorphism in controls. However, in T2DM patients had decreased HDL-c concentration and increased TC/HDL-c ratio, with carriers of the $\mathrm{T}$ allele (non $\mathrm{C} / \mathrm{C}$ ) having higher HLD-c and lower TC/HDL-c ratio values than C/C homozygotes ( $\mathrm{p}=0.0047$ and 0.0041 , respectively).

We further examined the potential associations between lipid parameters with dyslipidemia and rs4731702 genotypes in T2DM patients. As shown in Figure 3, HDL-c levels were substantially higher in T2DM patients, without dyslipidemia, carrying the genotype non-C/C. In opposite, TC and LDL-c levels were lower in non-C/C carriers.

Figure 4 shows the relation between TC/HDL-c and TG/HDL-c ratios with dyslipidemia and rs4731702genotypes in T2DM patients. Both ratios were lower in those T2DM patients that had no dyslipidemia, but carrying the genotype non-C/C.

\section{Discussion}

Herein we performed an association study between a SNP located in the non-coding region of the transcription factor KLF14 gene and lipid pattern in T2DM patients residing in San Luis, Argentina.

The most common pattern of dyslipidemia in type 2 diabetic patients is elevated triglyceride and decreased HDL-c concentrations. Diabetic patients have elevated levels

Table 6. Anthropometric and clinical characteristics by the $K L F 14$ polymorphism in controls and Type 2 Diabetes Mellitus. ${ }^{a}$

\begin{tabular}{ccccccc}
\hline & \multicolumn{3}{c}{ Control $(\mathrm{n}=47)$} & \multicolumn{3}{c}{ T2DM (n=26) } \\
\cline { 2 - 7 } C/C & Non C/C & p & C/C & Non C/C & p \\
\hline BMI & $24.96 \pm 3.17$ & $26.65 \pm 3.81$ & 0.4709 & $28.69 \pm 3.26$ & $27.69 \pm 3.66$ & 0.2729 \\
FPG (mg/dL) & $88.40 \pm 9.14$ & $88.14 \pm 10.47$ & 0.7686 & $161.06 \pm 67.28$ & $157.16 \pm 91.82$ & 0.5982 \\
TG (mg/dL) & $138.88 \pm 63.05$ & $137.41 \pm 86.92$ & 0.5637 & $238.34 \pm 45.44$ & $205.66 \pm 50.64$ & 0.1590 \\
TC (mg/dL) & $206.11 \pm 68.23$ & $193.54 \pm 33.38$ & 0.7686 & $216.11 \pm 34.27$ & $184.94 \pm 42.26$ & 0.0626 \\
HDL-c (mg/dL) & $48.36 \pm 10.94$ & $50.53 \pm 7.76$ & 0.3238 & $37.28 \pm 2.01$ & $41.36 \pm 5.24$ & 0.0047 \\
LDL-c (mg/dL) & $130.97 \pm 57.68$ & $118.14 \pm 28.90$ & 0.8368 & $134.95 \pm 38.21$ & $99.24 \pm 34.52$ & 0.0679 \\
VLDL-c (mg/dL) & $27.78 \pm 12.61$ & $27.48 \pm 17.38$ & 0.5637 & $47.67 \pm 9.06$ & $41.12 \pm 10.14$ & 0.1388 \\
TG/HDL-c ratio & $2.92 \pm 1.44$ & $2.61 \pm 1.44$ & 0.3937 & $6.39 \pm 1.17$ & $5.26 \pm 1.47$ & 0.0781 \\
TC/HDL-c ratio & $4.31 \pm 1.25$ & $3.90 \pm 0.70$ & 0.3400 & $5.99 \pm 1.23$ & $5.26 \pm 1.47$ & 0.0041 \\
\hline
\end{tabular}

${ }^{a}$ Data are shown as mean \pm standard deviation. BMI, body mass index; FPG, fasting plasma glucose; TG, triglycerides; TC, total cholesterol; HDL-c, high-density lipoprotein; LDL-c, low-density lipoprotein; VLDL-c, very lowdensity lipoprotein. 


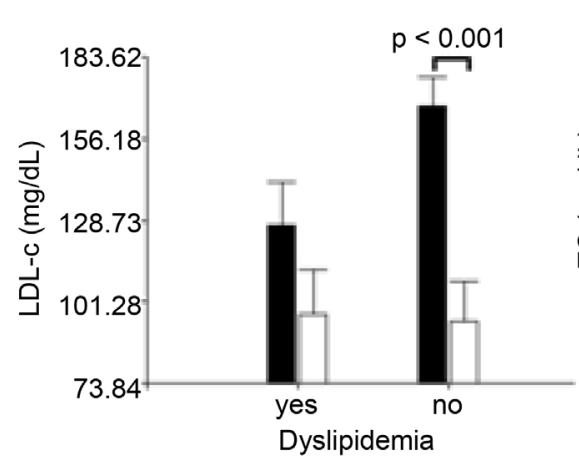

(a)

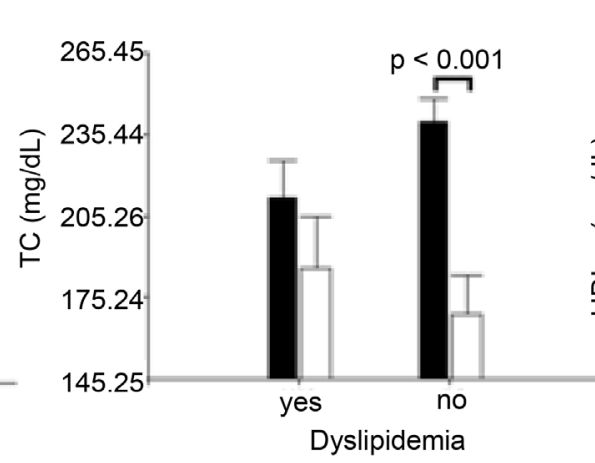

(b)

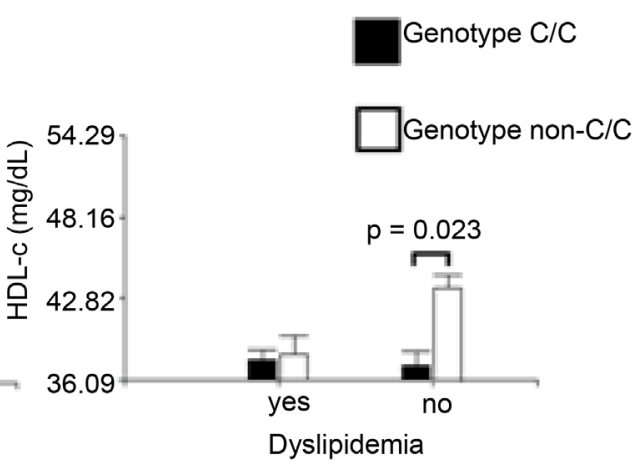

(c)

Figure 3. Concentrations of (a) LDL-c, (b) TC and (c) HDL-c according to dyslipidemia and genotypes in T2DM patients. Data are shown as mean \pm SEM. LDL, low-density lipoprotein; TC, total cholesterol; HDL, high-density lipoprotein.

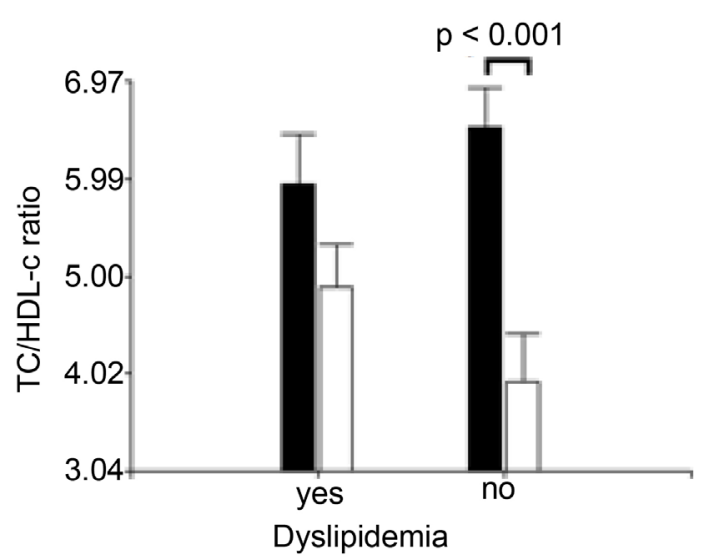

(a)

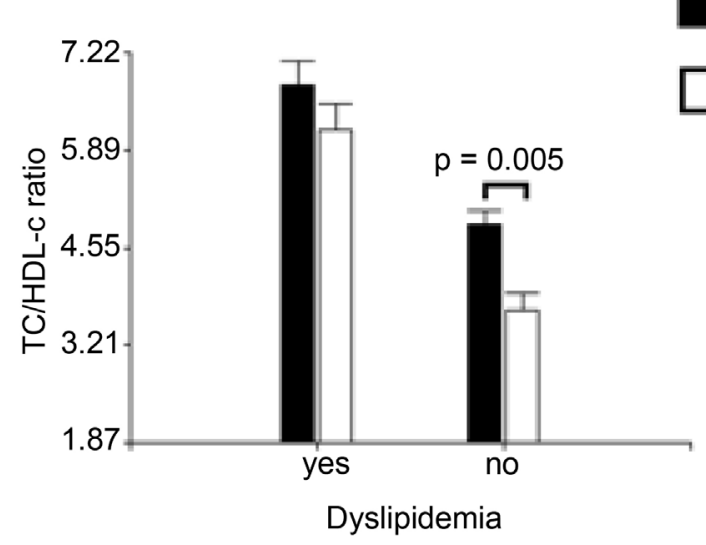

(b)

Figure 4. (a) TC/HDL-c ratio, according dyslipidemia in diabetic parientes. (b) TG/HDL-c ratio, according dyslipidemia and genotypes in diabetic patients. Data are shown as mean \pm SEM. TC, total cholesterol; HDL-c, high-density lipoprotein; TG, triglycerides.

of non-HDL cholesterol (LDL plus VLDL) [16].

Our study showed that our T2DM patients had increased TG and decreased HDL-c concentrations that are in agreement with the well-known relationship between the metabolism of TG-rich lipoproteins and the maturation of HDL-c particles [17]. Consistent with this view, our data showed that compared to controls T2DM patients have more TG, VLDL-c and LDL-c concentrations, higher BMI but lower HDL-c. These lipid patterns increase the risk of T2DM.

The "vicious cycle" hypothesis establishes that dyslipidemia leads to insulin resistance that leads to hyperinsulinemia. Any strategy to break this vicious cycle may offer unique opportunities to preventing T2DM and, thus its complications [18] [19].

Overproduction of VLDL-c, predominantly TG-rich large VLDL-c particles, induces the cascade of events that leads to abnormalities of other plasma lipoproteins. The accumulation of VLDL-c in plasma and decreased lipoprotein lipase (LPL) activity impair the catabolism of chylomicrons. Highly atherogenic small dense LDL-c is generated from VLDL-c particles by the activity of LPL, cholesteryl esther transfer protein (CETP) 
and hepatic lipase (HL). When hypertriglyceridemia occurs, accelerated lipid transfer generates TG-enriched HDL-c particles. This enhances HDL-c catabolism mediated by HL and endothelial lipase. Low HDL is an integral part of the atherogenic lipid profile in T2DM patients.

Earlier studies showed that in the dyslipidemia associated to T2DM and metabolic syndrome, HDL-c particles were depleted of CEs and ApoA-I, but enriched in TG [20]. In our study, we observed that the TG/HDL-c ratio was higher in type 2 diabetic patients than controls. This is in agreement with the observations by McLaughlin et al. (2005). These authors proposed that TG/HDL-c ration is an indicator of insulin resistance; and also an indicator of highly atherogenic small and dense LDL particles [21]. In addition, the TC/HDL-c ratio, an atherogenic index, was increased in T2DM patients, which suggest a higher risk for cardiovascular diseases in these patients. Dyslipidemia may lead to IR by causing inflammation, endoplasmic reticulum stress and lipotoxicity [19]. On the other hand, IR causes increased TG and plasma free fatty acids levels and decreased HDL-c. Free fatty acids are inflammogenic by activating toll-like receptor 2 in immune innate cells and promote expression of inflammation mediators. Altered lipid profile and increased inflammation and insulin resistance may probe again the "vicious cycle" hypothesis of the development of T2DM.

The KLF14 gene has recently elicited significant attention since extensive genetic studies in humans identified a central role of $K L F 14$ in the development of metabolic diseases, in particular those that regulate lipid metabolism. In fact, because of KLF14 contribution to metabolic diseases, it has been recently referred to as a "conductor of the metabolic syndrome orchestra" [22].

Gou et al. (2015) observed that KLF14 is downregulated in dyslipidemia mouse models and found that overexpression of KLF14 increases HDL-c levels by upregulating hepatic ApoA-I levels. To determine the contribution of hepatic KLF14 to both ApoA-I and HDL-c production, they generated $K L F 14$ knock-out mice which results in reduced plasma HDL-c concentration. Thus, the combined results of experiments using a wide variety of complementary genetic approaches firmly establish a regulatory role for KLF14 in HDL-c functionality and atherosclerosis [23]. In our study, T2DM patients have dyslipidemia, which could be related to down-regulation of KLF14 and, consequently decreased levels of HDL-c.

The results of large-scale GWAS indicated that $K L F 14$ may play a role in the pathogenesis of insulin resistance and T2DM. Yang et al. (2015) found reduced KLF14 mRNA and protein in both muscle and adipose tissue of T2DM patients. Reduced KLF14 expression was accompanied of low adiponectin expression, a known insulin sensitizer, thus increased insulin resistance [24].

It has been reported that prolonged cell incubation with insulin or glucose leads to insulin resistance, as shown by reduced glucose uptake and impaired insulin signaling [25]. Furthermore, Yang et al. (2015) found that KLF14 overexpression in Hepa1-6 cells partly prevented the inhibition of glucose uptake induced by high glucose and high insulin [24]. 
The present results show that the alterations observed in the lipoprotein profile may be related to the lower $K L F 14$ activity in T2DM patients as a consequence of dyslipidemia. It is also possible that insulin resistance may cause resistance to KLF14 actions, leading to its down-regulation.

The genotypic and allelic frequencies of KLF14 rs4731702 SNP in Argentinean populations are rarely known. According to the HapMap data, the minor T allele frequency of this SNP was 36.7\% in Chinese, 30.0\% in Japanese, 23.3\% in Yoruba, and $45.0 \%$ in European population. Kong et al. (2009) demonstrated that the frequency of $\mathrm{T}$ allele was $56.1 \%$ in normal Icelanders [11].

Chen et al. (2012) reported that the allelic frequencies of KLF14 rs4731702 SNP were different between atherosclerotic cardiovascular disease and control groups in Beijing and Taizhou Chinese. Moreover, the minor $\mathrm{T}$ allele frequency in myocardial infarction and ischemic stroke groups in these populations was lower than that in their corresponding control groups. The frequency of $\mathrm{T}$ allele was $31.5 \%, 29.1 \%$, and $30.2 \%$ in the three control groups, respectively [5].

In the present study, we showed that the T allele frequency of KLF14 rs4731702 SNP in control group was $45.0 \%$, which was similar to the HapMap data in European population, probably because most Argentinean are of European origin, and are either descendents of colonial-era settlers and/or of the 19th and 20th century immigrants from Europe. Indeed, over 90\% of the Argentina's population has European ethnicity.

In our T2DM patients, the distribution of KLF14 genotypes was similar to the controls, which does not suggest the occurrence of any linkage disequilibrium between the $K L F 14$ gene and those that might determine T2DM.

It was previously shown that $K L F 14$ is a master trans-regulator of multiple genes that are associated with metabolic phenotypes in adipose tissue [9]. These findings suggest that the role of $K L F 14$ could be a central regulator of lipid metabolism in health and disease.

Among those genes identified by GWAS, the T allele of KLF14 rs4731702 is significantly associated with elevated HDL-c concentration and decreased risk of cardiovascular disease and T2DM. Another association with T2DM established by the Diabetes Genetics Replication and Meta-analysis (DIAGRAM) consortium is allele C [4] [5] [11].

Rare studies have previously reported the direct effect of KLF14 rs4731702 SNP on serum lipid pattern in T2DM patients. The present study showed a significant association between the rs4731702 SNP and lipid pattern in T2DM patients. Our T2DM patients that carry the T allele (non-C/C) have higher HDL-c concentration and lower TC/HDL-c ratio than those $\mathrm{T}$ allele non-carriers (C/C). They also have a tendency of lower TC and LDL-c concentrations, and lower TG/HDL-c ratio, than those T allele non-carriers. Previous functional studies found that the maternally transmitted $\mathrm{T}$ allele of rs4731702 SNP is associated with increased expression of KLF14 in adipose tissue, indicating the presence of cis expression quantitative trait loci (eQTL) [11]. Small et al. (2011) reported that the T2DM- and HDL-c-associated cis-acting eQTL of KLF14 acts 
as a master trans-regulator of adipose gene expression. They studied subcutaneousadipose biopsies from 776 female twins of European ancestry as well as a smaller replication sample. Their results suggested a trans-causal link between KLF14 expression and ten genes (TPMT, ARSD, SLC7A10, C8orf82, APH1B, PRMT2, NINJ2, KLF13, GNB1, MYL5). These genes were associated with a variety of metabolic syndrome traits including obesity, dyslipidemia, and insulin resistance. Moreover, using large scale GWAS data, they found that five of those ten genes had nearby SNPs that were associated with key metabolic syndrome traits at genome-wide significance [9].

Taken together, the rs4731702 SNP may act in cis to influence the KLF14-associated trans-regulatory network that control lipid metabolism. Chen et al. (2012) found that the rs4731702-T allele is consistently associated to an increased HDL-c concentration [5]. Interestingly, the T2DM-risk C allele of the rs4731702 SNP correlated fairly well with lower expression of KLF14 in adipose tissue [11]. Then, we can assume that our T2DM patients with genotype $\mathrm{C} / \mathrm{C}$ may have decreased expression of KLF14, thus lower levels of HDL-c as compared to the non-C/C (T allele carriers) genotype.

The risk $\mathrm{C}$ allele at $K L F 14$ was associated with reduced insulin sensitivity and it appears to have a primary effect on insulin action, which is not driven by obesity [10]. This is in agreement with our results that shows that T2DM patients, with the C/C genotype, have a tendency of insulin resistance according to TG/HDL-c ratio, an indicator of insulin resistance or/and reduced insulin sensitivity as compared to the non-C/C ( $\mathrm{T}$ allele carriers) genotype.

Our T2DM patients have increased TC/HDL-c ratio. This suggests a higher risk for cardiovascular diseases in this group. When compared T2DM patients according to genotypes, the $\mathrm{C} / \mathrm{C}$ carriers have higher TC/HDL-c ratio. This finding suggest that increased TC/HDL-c ratio in $\mathrm{C} / \mathrm{C}$ carriers may be associated with an increased risk of cardiovascular diseases in patients having the $\mathrm{C}$ allele.

However, the biological function and detailed role of KLF14 rs4731702 SNP in lipid metabolism need to be further explored.

\section{Conclusions}

T2DM patients having the C/C genotype of KLF14 (rs4731702) may have a worsen insulin resistance and be susceptible to more serious pathophysiological consequences regarding lipid metabolism. The biological role of $K L F 14$, as an insulin-sensitizing transcription factor, could potentially be envisioned as a novel therapeutic target for management, treatment and prevention of insulin resistance and related pathologies, such as highly susceptible T2DM populations.

Finally, genotyping of the rs 4731702 polymorphism of the KLF14 gene can be of high predictive and interventional value of cardiovascular complications in our, and probably other, populations which have a high prevalence of T2DM.

\section{References}

[1] Scully, T. (2012) Diabetes in Numbers. Nature, 485, S2-S3. https://doi.org/10.1038/485S2a 
[2] Lusis, A.J., Attie, A.D. and Reue, K. (2008) Metabolic Syndrome: From Epidemiology to Systems Biology. Nature Reviews Genetics, 9, 819-830. https://doi.org/10.1038/nrg2468

[3] Chasman, D.I., Paré, G., Mora, S., Hopewell, J.C., Peloso, G., Clarke, R., et al. (2009) Forty-Three Loci Associated with Plasma Lipoprotein Size, Concentration, and Cholesterol Content in Genome-Wide Analysis. PLoS Genetics, 5, e1000730. https://doi.org/10.1371/journal.pgen.1000730

[4] Teslovich, T.M., Musunuru, K., Smith, A.V., Edmondson, A.C., Stylianou, I.M., Koseki, M., et al. (2010) Biological, Clinical and Population Relevance of 95 Loci for Blood Lipids. Nature, 466, 707-713. https://doi.org/10.1038/nature09270

[5] Chen, X., Li, S., Yang, Y., Yang, X., Liu, Y., Liu, Y., et al. (2012) Genome-Wide Association Study Validation Identifies Novel Loci for Atherosclerotic Cardiovascular Disease. Journal of Thrombosis and Haemostasis, 10, 1508-1514.

https://doi.org/10.1111/j.1538-7836.2012.04815.x

[6] Huang, P., Yin, R.X., Huang, K.K., Zeng, X.N., Guo, T., Lin, Q.Z., et al. (2013) Association of the KLF14 rs4731702SNP and Serum Lipid Levels in the Guangxi Mulao and Han Populations. BioMed Research International, 2013, Article ID: 231515. https://doi.org/10.1155/2013/231515

[7] de Assuncao, T.M., Lomberk, G., Cao, S., Yaqoob, U., Mathison, A., Simonetto, D.A., et al. (2014) New Role for Kruppel-Like Factor 14 as a Transcriptional Activator Involved in the Generation of Signaling Lipids. Journal of Biological Chemistry, 289, 15798-15809. https://doi.org/10.1074/jbc.M113.544346

[8] McConnell, B.B. and Yang, V.W. (2010) Mammalian Kruppel Like Factors in Health and Diseases. Physiological Reviews, 90, 1337-1381. https://doi.org/10.1152/physrev.00058.2009

[9] Small, K.S., Hedman, A.K., Grundberg, E., Nica, A.C., Thorleifsson, G., Kong, A., et al. (2011) Identification of an Imprinted Master Trans Regulator at the KLF14 Locus Related to Multiple Metabolic Phenotypes. Nature Genetics, 43, 561-564. https://doi.org/10.1038/ng.833

[10] Voight, B.F., Scott, L.J., Steinthorsdottir, V., Morris, A.P., Dina, C., Welch, R.P., et al. (2010) Twelve Type 2 Diabetes Susceptibility Loci Identified through Large-Scale Association Analysis. Nature Genetics, 42, 579-589. https://doi.org/10.1038/ng.609

[11] Kong, A., Steinthorsdottir, V., Masson, G., Thorleifsson, G., Sulem, P. and Besenbacher, S. (2009) Parental Origin of Sequence Variants Associated with Complex Diseases. Nature, 462, 868-874. https://doi.org/10.1038/nature08625

[12] Seino, Y., Nanjo, K., Tajima, N., Kadowaki, T., Kashiwagi, A., Araki, E., et al. (2010) Report of the Committee on the Classification and Diagnostic Criteria of Diabetes Mellitus. Journal of Diabetes Investigation, 1, 212-228. https://doi.org/10.1007/s13340-010-0006-7

[13] Clinical Guidelines on the Identification, Evaluation, and Treatment of Overweight and Obesity in Adults (1998) The Evidence Report. National Institutes of Health. Obesity Research, 6, 51S-209S.

[14] Friedewald, W.T., Levy, R.I. and Fredrickson, D.S. (1972) Estimation of the Concentration of Low-Density Lipoprotein Cholesterol in Plasma, without Use of the Preparative Ultracentrifuge. Clinical Chemistry, 18, 499-502.

[15] Expert Panel on Detection (2001) Expert Panel on Detection, Evaluation and Treatment of High Blood Cholesterol in Adults: Executive Summary of the Third Report of the National Cholesterol Education Program Expert Panel on Detection, Evaluation and Treatment of High Blood Cholesterol in Adults (Adult Treatment Panel I II). Journal of the American Medical Association, 285, 2486-2497. https://doi.org/10.1001/jama.285.19.2486 
[16] American Diabetes Association (2003) Management of Dyslipidemia in Adults With Diabetes. Diabetes Care, 26, s83-s86. https://doi.org/10.2337/diacare.26.2007.S83

[17] Rye, K.A. and Barter, P.J. (2004) Formation and Metabolism of Prebeta Migrating, Lipid Poor Apolipoprotein A-I. Arteriosclerosis, Thrombosis, and Vascular Biology, 24, 421-428. https://doi.org/10.1161/01.ATV.0000104029.74961.f5

[18] Steiner, G. and Vranic, M. (1982) Hyperinsulinemia and Hypertriglyceridemia a Vicious Cycle with Atherogenic Potential. International Journal of Obesity, 6, 117-124.

[19] Li, N., Fu, J., Koonen, D.P., Kuivenhoven, J.A., Snieder, H. and Hofker, M.H. (2014) Are Hypertriglyceridemia and Low HDL Causal Factors in the Development of Insulin Resistance? Atherosclerosis, 233, 130-138. https://doi.org/10.1016/j.atherosclerosis.2013.12.013

[20] Kontush, A. and Chapman, M.J. (2006) Functionally Defective HDL: A New Therapeutic Target at the Crossroads of Dyslipidemia, Inflammation and Atherosclerosis. Pharmacological Reviews, 58,342-374. https://doi.org/10.1124/pr.58.3.1

[21] McLaughlin, T., Reaven, G., Abbasi, F., Lamendola, C., Saad, M., Waters, D., et al. (2005) Is There a Simple Way to Identify Insulin-Resistant Individuals at Increased Risk of Cardiovascular Disease? American Journal of Cardiology, 96, 399-404. https://doi.org/10.1016/j.amjcard.2005.03.085

[22] Civelek, M. and Lusis, A.J. (2011) Conducting the Metabolic Syndrome Orchestra. Nature Genetics, 43, 506-508. https://doi.org/10.1038/ng.842

[23] Guo, Y., Fan, Y., Zhang, J., Lomberk, G.A., Zhou, Z., Sun, L., et al. (2015) Perhexiline Activates KLF14 and Reduces Atherosclerosis by Modulating ApoA-I Production. Journal of Clinical Investigation, 125, 3819-3830. https://doi.org/10.1172/JCI79048

[24] Yang, M., Ren, Y., Lin, Z., Tang, C., Jia, Y., Lai, Y., et al. (2015) Krüppel-Like Factor 14 Increases Insulin Sensitivity through Activation of PI3K/Akt Signal Pathway. Cell Signaling, 27, 2201-2208. https://doi.org/10.1016/j.cellsig.2015.07.019

[25] Amatruda, J.M., Newmeyer, H.W. and Chang, C.L. (1982) Insulin-Induced Alterations in Insulin Binding and Insulin Action in Primary Cultures of Rat Hepatocytes, Diabetes, 31, 145-148. https://doi.org/10.2337/diab.31.2.145

\section{Submit or recommend next manuscript to OALib Journal and we will provide best service for you:}

- Publication frequency: Monthly

- 9 subject areas of science, technology and medicine

- Fair and rigorous peer-review system

- Fast publication process

- Article promotion in various social networking sites (LinkedIn, Facebook, Twitter, etc.)

- Maximum dissemination of your research work

Submit Your Paper Online: Click Here to Submit

Or Contact service@oalib.com 